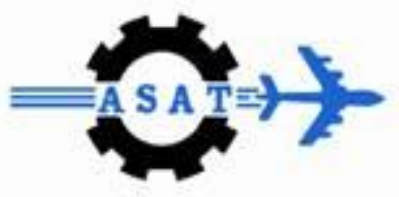

\title{
Modeling and Simulating Guidance Laws for Gun-Launched Guided Munitions
}

\author{
Hatem H. Daken ${ }^{*}$
}

\begin{abstract}
Models for selected guidance laws were designed and built using The Mathworks' SIMULINK. These guidance law blocks were used in an exterior ballistics model to evaluate the feasibility of utilizing body fixed seekers for shipboard gun-launched guided munitions based on the kinematic capability of candidate munitions to intercept and destroy highly maneuvering surface targets at close ranges and from different directions.
\end{abstract}

Keywords: SIMULINK, Guided Munitions, Guidance Blocks, Body-Fixed Seekers

\section{Nomenclature}

The following nomenclature is used in the simulation model of this article:

Attitude

Ae_T

$\mathrm{AOV}$

Ax, Ay

Ay_P_d

Gamma

L_D

LOS

n_c

n_L

n_T

$\mid$ r_T-r_P $\mid$

Side Slip

T_go

Ue_P, Ve_P

Ue_T, Ve_T

V_c

Xe_P, Ye_P

$\mathrm{Xe} \_\mathrm{T}, \mathrm{Ye} \_\mathrm{T}$

ZEMPLOS
Attitude angle of the projectile, degrees.

Lateral acceleration of the target, $\mathrm{m} / \mathrm{sec}^{2}$.

Angle between the projectile's axis and the line of sight, degrees.

Acceleration components of the projectile, $\mathrm{m} / \mathrm{sec}^{2}$.

Lateral acceleration of the projectile. Equals the guidance law block command acceleration limited to +2 and $-1 \mathrm{Gs}, \mathrm{m} / \mathrm{sec}^{2}$.

Angle between the velocity components of the projectile, degrees.

Lead angle of the projectile, degrees.

Line of sight angle measured from the North, $\mathrm{Y}$ axis. It is positive clockwise, degrees.

Guidance block projectile command acceleration, Gs.

Projectile's actual lateral acceleration, $\mathrm{m} / \mathrm{sec}^{2}$.

Target's actual lateral acceleration, $\mathrm{m} / \mathrm{sec}^{2}$, used only with some guidance law blocks.

Magnitude of the difference vector between the location vectors of the target and projectile, meters.

Side slip angle between the projectile velocity vector and its axis, degrees.

Time to target interception, seconds, used only with the TPNZEMPLOS guidance law block

Components of the velocity vector of the projectile, $\mathrm{m} / \mathrm{sec}$.

Components of the velocity vector of the target, $\mathrm{m} / \mathrm{sec}$.

Closing velocity between the projectile and target, $\mathrm{m} / \mathrm{sec}$

Components of the location vector of the projectile, meters.

Components of the location vector of the target, meters.

Zero error miss perpendicular to line of sight, meters

\footnotetext{
"Ph.D., Senior Structural Analysis Scientist/Engineer, Boeing Commercial Airplanes, The Boeing Company, Seattle, WA, USA (work was performed while working as the Principal Engineer, Defense Technology Inc., DTI, Arlington, VA, USA), hatemdaken@aol.com 


\section{Introduction}

The incident of the USS Cole, an Arleigh Burke-class Aegis-equipped guided missile destroyer DDG 76, in Aden harbor on 12 October 2000 made the U.S. Navy cognizant of the threat to its surface vessels being attacked by fast, small, and highly maneuverable surface targets in high numbers and from different directions. This incident prompted the U.S. Navy to assess the capability of candidate shipboard gun-launched guided munitions to intercept and destroy such hostile surface targets at close ranges and in different directions.

The Naval Surface Fire Support Systems (NSFS) Program Office PMS 529, which is currently reorganized into the Program Executive Office (PEO) for Integrated Warfare Systems (IWS) Code PEO IWS 3C, initiated an effort to: (1) evaluate the merits of selected guidance law blocks; (2) its impact on the kinematic capability of candidate munitions ${ }^{1,2}$ to intercept and destroy surface targets under different attack scenarios; and (3) its compatibility with candidate body-fixed seekers. This effort was accomplished as part of PMS 529 SBIR (Small Business Innovation Research) program.

The major function of the guidance law block is to compute the input parameters required by the autopilot to maneuver the projectile to intercept and destroy its target. The geometry of the problem is illustrated in Figure 1. A 2D model was opted for because: (1) the target ranges in these simulations are much lower than the range capability of candidate projectiles; (2) all the guidance laws selected below are formulated in 2D; and (3) Reference [6] entails only one 3D guidance law, which did not offer much of a choice. The gun elevation angle was assumed to be zero when the projectile is launched. The effect of gravity on the projectile was neglected and it was assumed to be surface skimming. The effects of aerodynamic lift and drag were considered in the XY plane only. We strongly believe these simplifications did not have any negative impacts on the validity of the simulation results.

The guidance laws selected for this modeling and simulation effort are listed below ${ }^{3,45}$ : Figure 10 illustrate these guidance law blocks, their inputs, and outputs

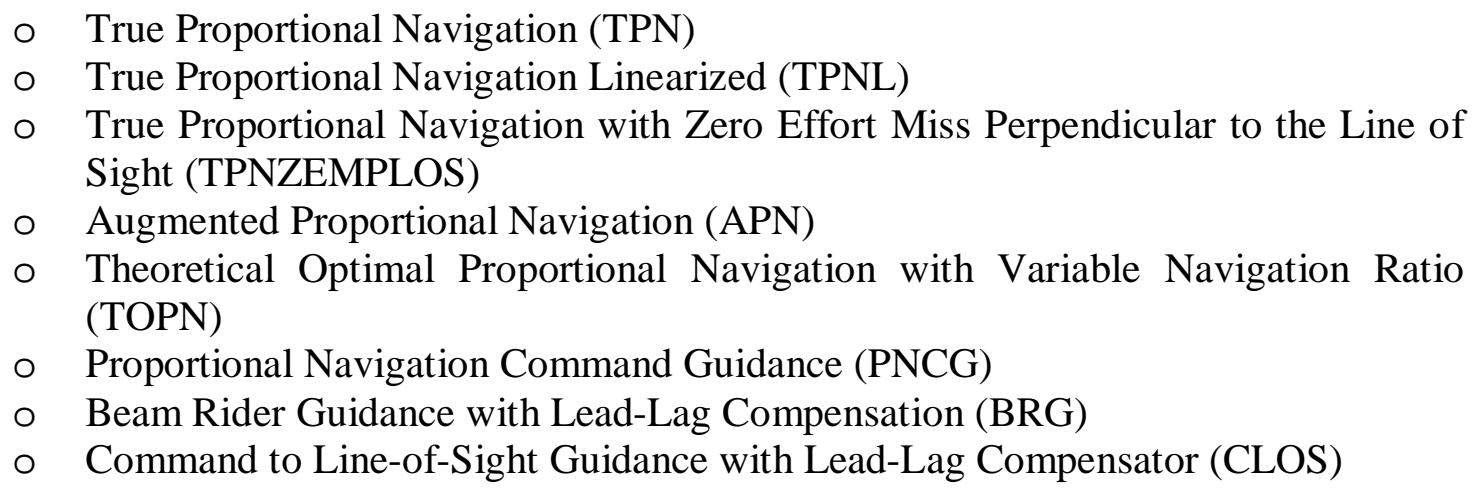

\section{Description of Model Key Elements}

We used MATLAB's SIMULINK version 5.0.1 to develop the guidance law blocks shown in Figure 10. The mathematical formulations of these guidance laws can found in References 3, 4, and 5. The model is comprised from the following modules, whose general architecture and layout is illustrated in Figures 10 through 15: 


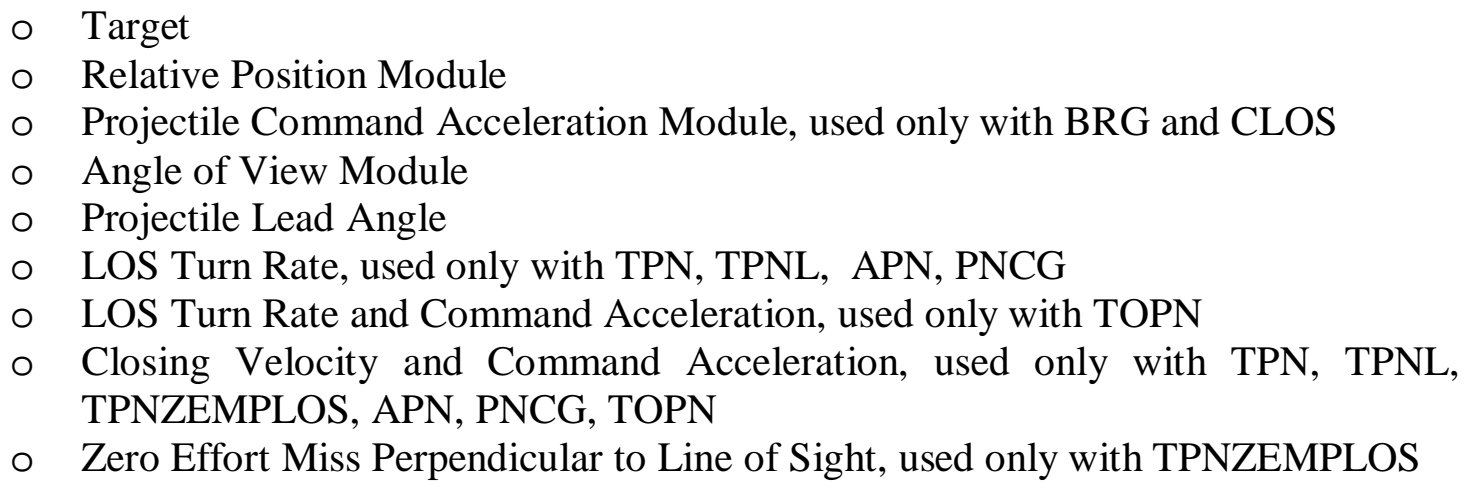

This model handles all iterative DO loops using vectors, which reduces the processing load at each time step. It provides the capability to compute the variation in the angle of view, projectile attitude angle, line of sight angle, side slip angle, command acceleration, current position and velocity components of the target and projectile versus the time elapsed since the projectile was launched. The building blocks illustrated in Figures 10 through 15 at the end of this article represent the general architecture and layout of this model. Including all the layers and details in this article was not possible because of space limitations.

\section{Target}

This module permits the user to input the target's initial location, its maximum forward speed, and course. It also allows the user to input the amplitude and frequency of the zigzagging or weaving maneuvers, start and end times and course change angle of evasive maneuvers.

\section{Relative Position}

This module computes the line of sight angle (LOS) and the magnitude of the location difference vector ( $\left.\mathrm{r}_{-} \mathrm{T}-\mathrm{r} \_\mathrm{P}\right)$ using the current locations of the target $\left(\mathrm{Xe}, \mathrm{Ye} \_\mathrm{T}\right)$ and the projectile (Xe,Ye_P).

\section{Projectile Command Acceleration}

Computes the command lateral acceleration of the projectile (n_c) based on the current location and velocity of the target $\left(\mathrm{Xe}, \mathrm{Ye} \_\mathrm{T}\right)\left(\mathrm{Ue}, \mathrm{Ve} \_\mathrm{T}\right)$ and projectile $\left(\mathrm{Xe}, \mathrm{Ye} \_\mathrm{P}\right)\left(\mathrm{Ue}, \mathrm{Ve} \_\mathrm{P}\right)$ and the lateral acceleration of the target $\left(\mathrm{Ae}_{-} \mathrm{T}\right)$.

\section{Angle of View}

Computes (AOV) and (Gamma) based on the current location (Xe,Ye_P) and velocity $\left(\mathrm{Ue}, \mathrm{Ve} \_\mathrm{P}\right)$ of the projectile and the current location of the target $\left(\mathrm{Xe}, \mathrm{Ye} \_\mathrm{T}\right)$.

\section{Projectile Lead Angle}

Computes (L_D) based on the current velocity of the projectile ( $\left(\mathrm{Ue}, \mathrm{Ve} \_\mathrm{P}\right)$ and the target (Ue,Ve_T) and the lateral acceleration of the target $\left(\mathrm{Ae}_{-} \mathrm{T}\right)$.

\section{LOS Turn Rate}

Computes (LOS_dot) based on the current location (Xe,Ye_T) and velocity (Ue,Ve_T) of the target and projectile (Xe,Ye_P) (Ue,Ve_P) and the closing velocity (V_c).

\section{Closing Velocity}

Computes (V_c) based on the current location (Xe,Ye_T) and velocity (Ue,Ve_T) of the target and the projectile (Xe,Ye_P) (Ue,Ve_P). 


\section{Zero Effort Miss Perpendicular to Line of Sight}

Computes (ZEMPLOS) and (T_go) based on the current location $\left(\mathrm{Xe}, \mathrm{Ye} \_\mathrm{T}\right)$ and velocity $\left(\mathrm{Ue}, \mathrm{Ve} \_\mathrm{T}\right)$ of the target and projectile $\left(\mathrm{Xe}, \mathrm{Ye} \_\mathrm{P}\right)\left(\mathrm{Ue}, \mathrm{Ve} \_\mathrm{P}\right)$ and the closing velocity $\left(\mathrm{V} \_\mathrm{c}\right)$.

\section{Model Initialization, Validation, and Results}

\section{Initialization}

Parameters that need to be entered manually are:

- Initial position of the target with respect to the naval vessel, which is assumed to be at the origin of the reference coordinate system

- Maximum forward speed of the target

- Sailing course of the target with respect to the North (positive clockwise)

- Maximum lateral acceleration of the target

- Amplitude and frequency of zigzagging or weaving maneuvers

- Start and stop of course change evasive maneuvers and course change angle

- Initial velocity and attitude of the projectile, $\mathrm{m} / \mathrm{sec}$ and radians, respectively

\section{Validation}

The model was validated by running a number of simulations involving stationary targets. These simulations proved that all guidance law blocks are capable of guiding the projectile to intercept these targets.

\section{Results}

The Tables 1 and 2 summarize the attack scenarios used to test the guidance law blocks and the interception results. Projectile initial velocity of $792 \mathrm{~m} / \mathrm{sec}$ was used in all simulations. The projectile was always fired in the target direction without any in-course lead advantage. The simulation was stopped when the projectile was within 1 meter or less from the target. This distance is less than what is needed to trigger the proximity fuse of the projectile. Simulation of the attack scenarios' parameters using the CLOS guidance law, target and projectile positions, guidance error, and the interception result are presented in Figures 2 through 5. Other CLOS simulation parameters, i.e. angle of view, projectile attitude, side slip angle, and the projectile's lateral acceleration, are depicted in Figures 6 through 9. Figure 7 entails a separate plot for the variation in the projectile attitude angle for each attack scenario simulation to magnify these small variations.

\section{Conclusions}

The modeling and simulation results satisfied the objective of evaluating the capability of different guidance law blocks to guide a shipboard gun-launched projectile to intercept highly maneuvering targets under different attack scenarios. It also allowed a precise prediction of the change in the angle of view magnitude from launch to intercept and permitted NSFS to select the body-fixed seekers that would match its standards and requirements. Though the 100\% kill distance of the MK 15 Phalanx Close-In Weapons System (CIWS) is classified, it is strongly believed that it is capable of engaging and destroying small and highly maneuvering surface targets at ranges from zero to one nautical mile and beyond. This makes it an excellent backup system for the 5" gun used in these simulations and explains the reason for limiting the attack scenarios to the 1-10 nautical mile range. 


\section{References}

[1] Corse, C. D. Jr., "Introduction to Shipboard Weapons," Naval Institute Press, Annapolis, Maryland, USA, 1975.

[2] Frieden, D. R. editor, "Principles of Naval Weapon Systems," Naval Institute Press, Annapolis, Maryland, USA, 1985.

[3] Merrill, G., "Principles of Guided Missile Design," Systems Preliminary Design Series, Van Nostrand Company, Toronto, Canada, 1960.

[4] Zarchan, P., "Tactical and Strategic Missile Guidance," $4^{\text {th }}$ Edition, American Institute of Aeronautics and Astronautics (AIAA), Reston, VA, USA, 2002.

[5] Lin, Ching-Fang, "Modern Navigational Guidance and Control Processing," Volume 2, Printce Hall Series in Advanced Navigation, Guidance, and Control, and their Applications, Printce Hall Inc., Upper Saddle River, NJ, USA, 1991.

[6] Duflos, E. et al, "3D Guidance Law Modeling," IEEE Transactions on Aerospace and Electronic Systems, Vol. 35, No. 1, January 1998, pages 72-83

Table 1: Parameters of the Attack Scenarios

\begin{tabular}{|c|c|c|c|c|c|c|c|c|c|c|}
\hline \multirow{3}{*}{ Attack Scenario } & \multicolumn{8}{|c|}{ Target Initial Parameters \& Evasive Maneuver } & \multicolumn{2}{|c|}{$\begin{array}{c}\text { Projectile } \\
\text { Parameters }\end{array}$} \\
\hline & $\mathrm{X}$ & $\mathrm{Y}$ & $\begin{array}{l}\stackrel{3}{0} \\
\frac{0}{0} \\
>\end{array}$ & 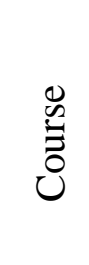 & 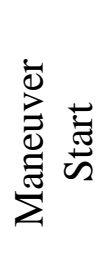 & 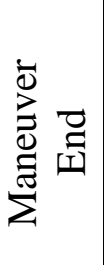 & 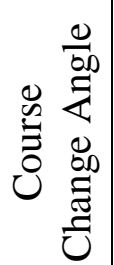 & Gs & 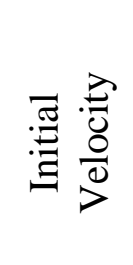 & 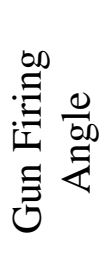 \\
\hline & \multicolumn{2}{|c|}{$\mathrm{nm}$} & knots & deg & \multicolumn{2}{|c|}{ sec } & deg & 1 & $\mathrm{~m} / \mathrm{sec}$ & deg \\
\hline 1 & 0 & 10 & \multirow{4}{*}{40} & 90 & \multirow{2}{*}{10} & \multirow{2}{*}{15} & 90 & \multirow{4}{*}{1} & \multirow{4}{*}{792} & 0 \\
\hline 2 & 5 & 5 & & -90 & & & -90 & & & -45 \\
\hline 3 & 1 & 1 & & -135 & \multirow{2}{*}{1} & \multirow{2}{*}{5} & -90 & & & -45 \\
\hline 4 & -1 & 1 & & 135 & & & -90 & & & 45 \\
\hline
\end{tabular}

Table 2: Interception Results

\begin{tabular}{c|c|c|c|c|c|c|c|c}
\hline \multirow{2}{*}{ Attack Scenario } & \multicolumn{7}{|c|}{ Guidance Law Block } \\
\cline { 2 - 10 } & TPN & TPNL & $\begin{array}{c}\text { TPNZEM } \\
\text { PLOS }\end{array}$ & APN & TOPN & PNCG & BRG & CLOS \\
\hline 1 & Kill & Kill & Kill & Kill & Kill & Kill & Kill & Kill \\
\hline 2 & Kill & Miss & Kill & Kill & Kill & Kill & Kill & Kill \\
\hline 3 & Kill & Miss & Kill & Miss & Miss & Kill & Miss & Kill \\
\hline 4 & Kill & Miss & Kill & Miss & Miss & Kill & Miss & Kill \\
\hline \hline
\end{tabular}




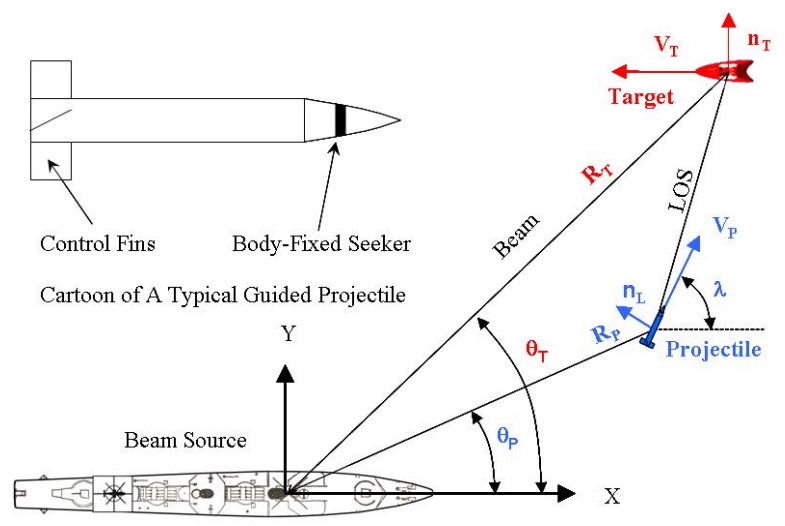

Figure 1: Geometry and Parameters of the 2D Interception Problem

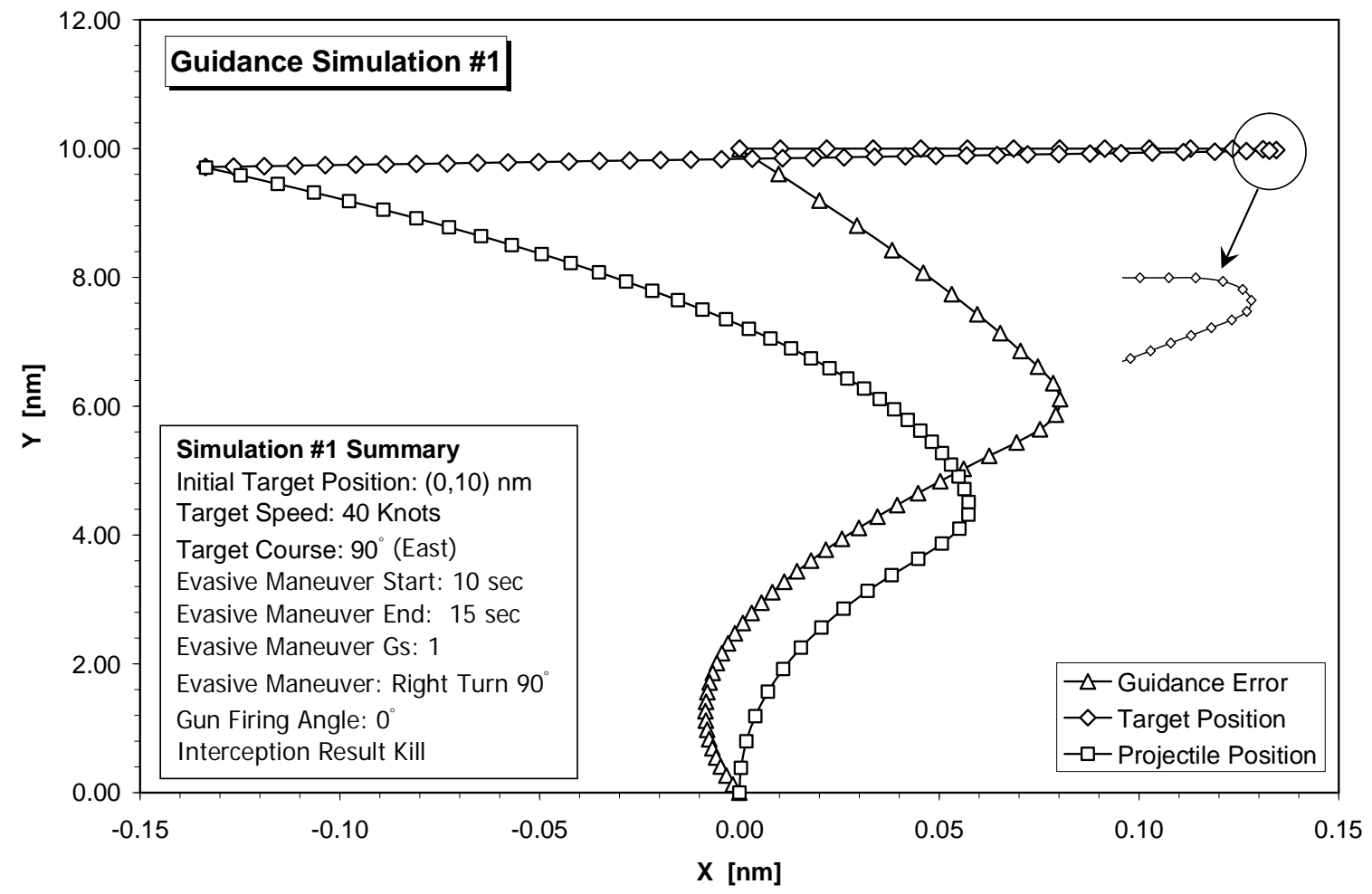

Figure 2: CLOS Simulation \#1 Parameters, Target and Projectile Positions, Guidance Error, and Interception Result 


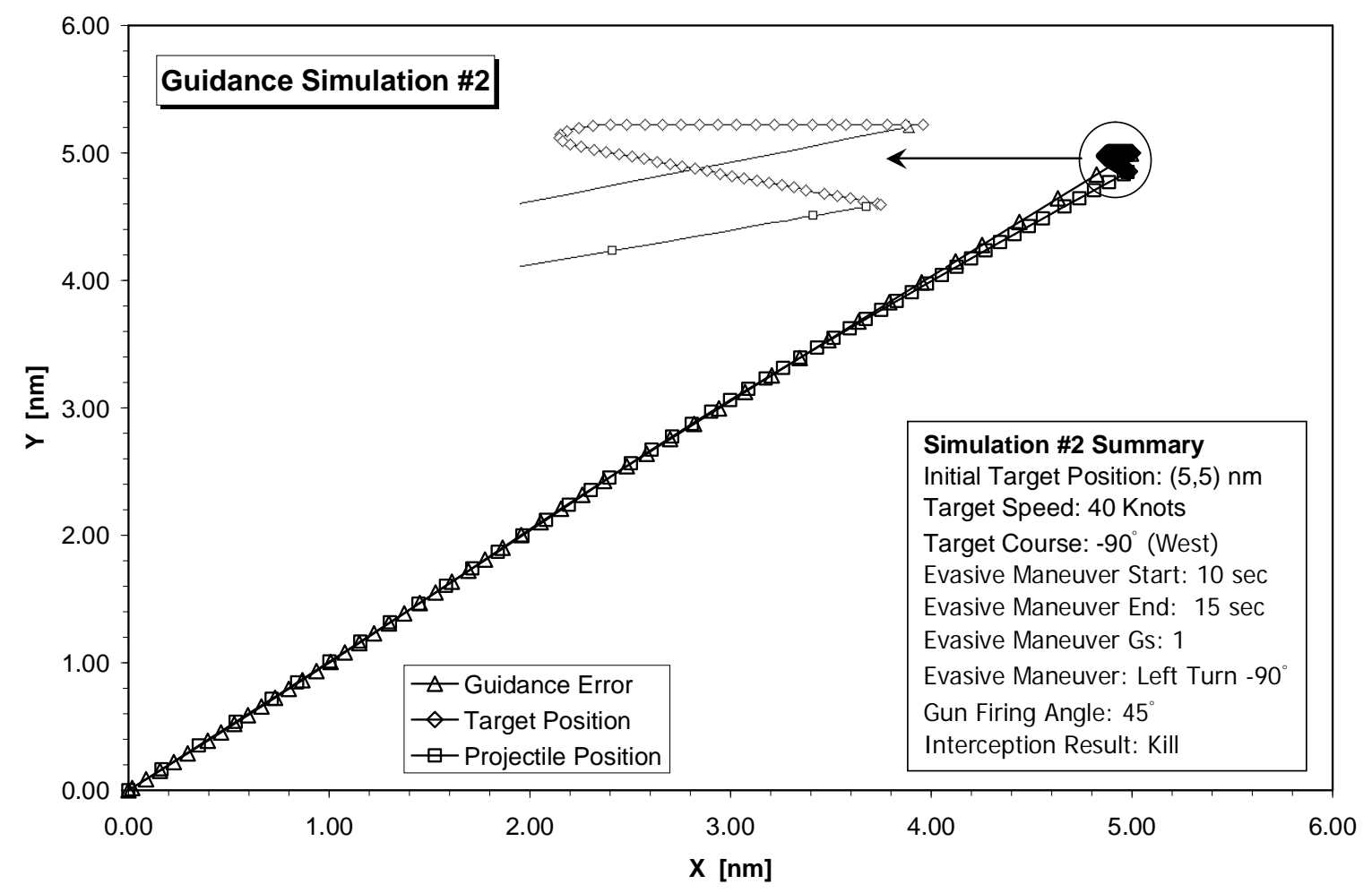

Figure 3: CLOS Simulation \#2 Parameters, Target and Projectile Positions, Guidance Error, and Interception Result

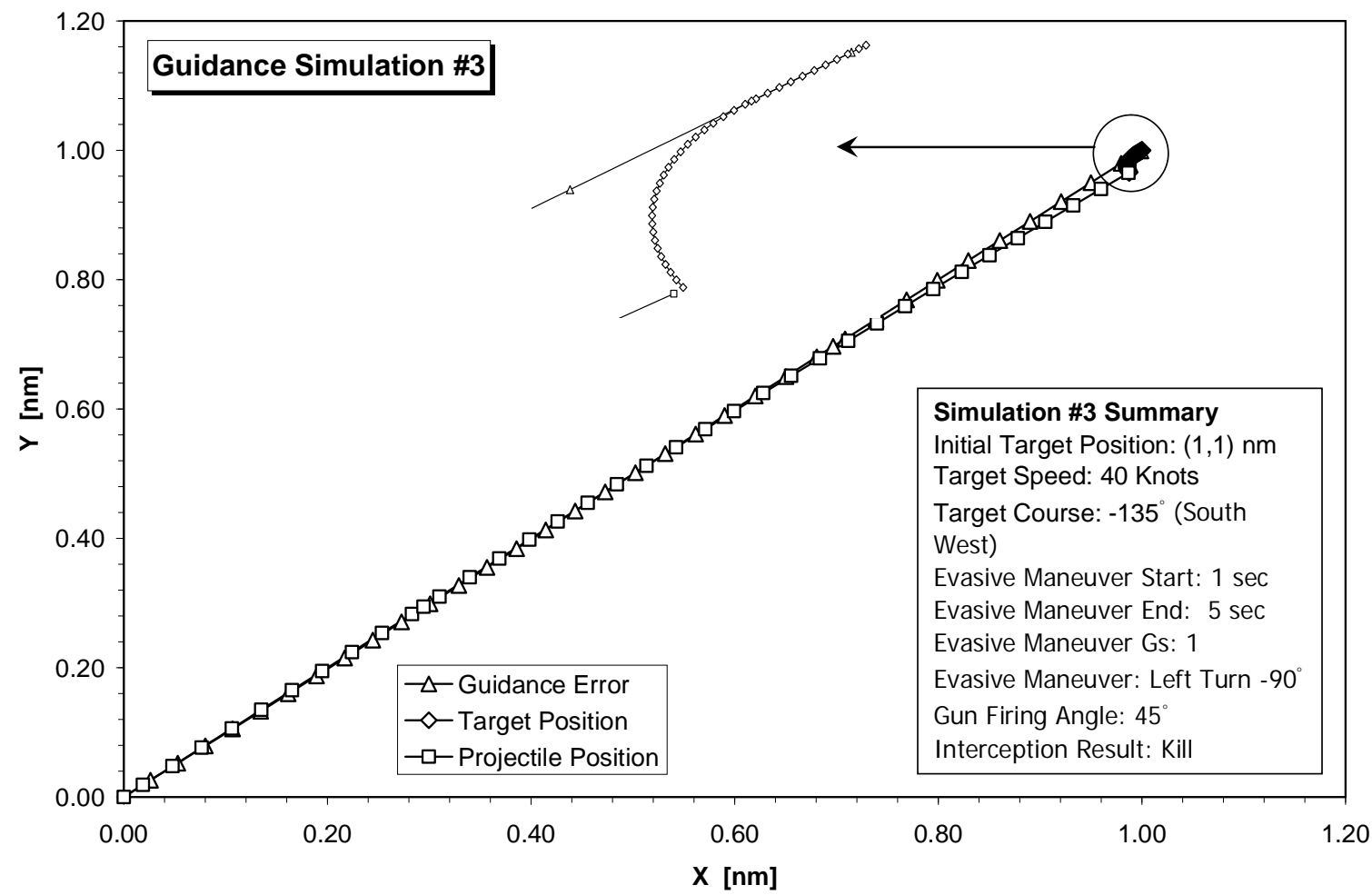

Figure 4: CLOS Simulation \#3 Parameters, Target and Projectile Positions, Guidance Error, and Interception Result 


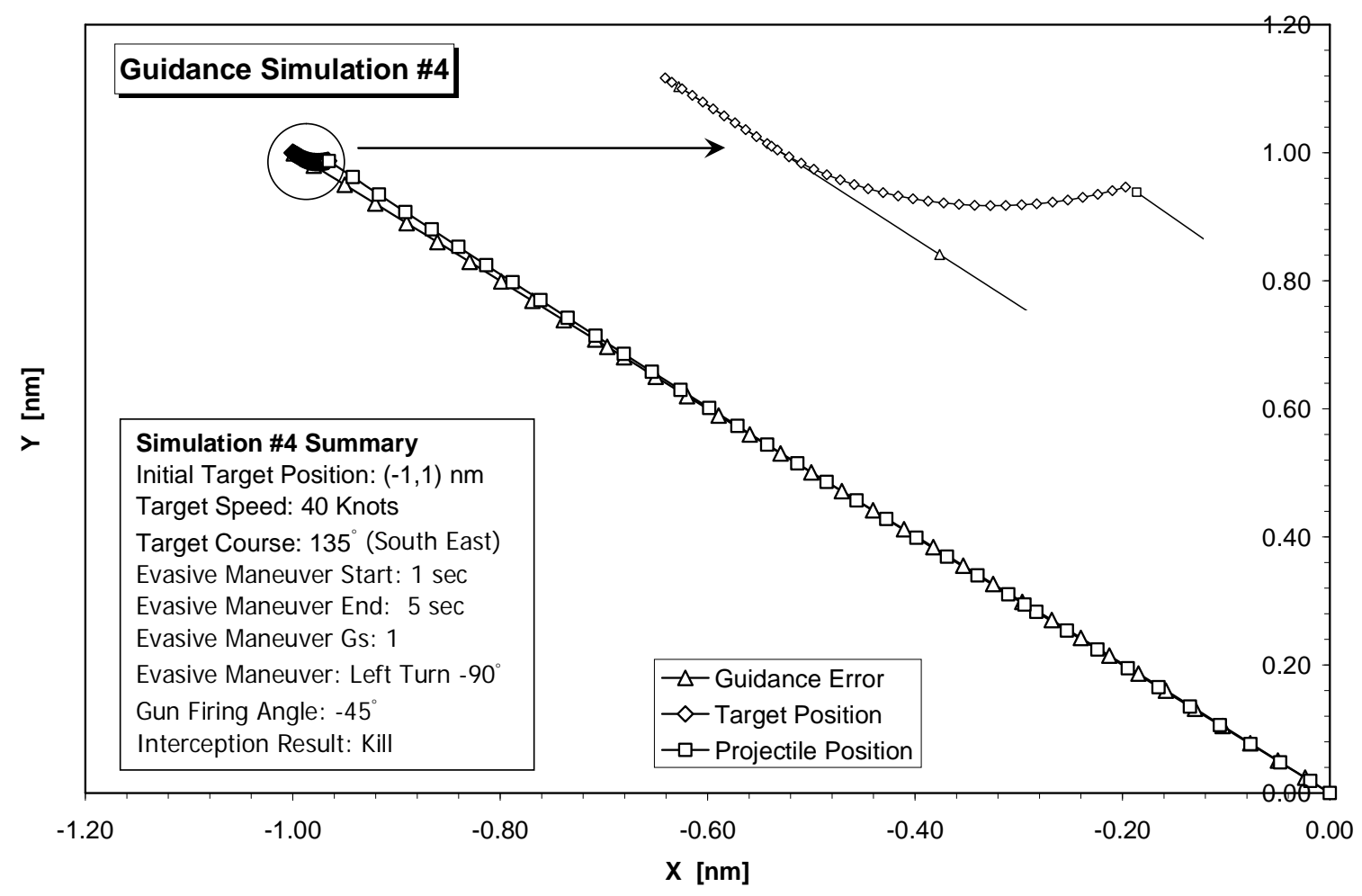

Figure 5: CLOS Simulation \#4 Parameters, Target and Projectile Positions, Guidance Error, and Interception Result

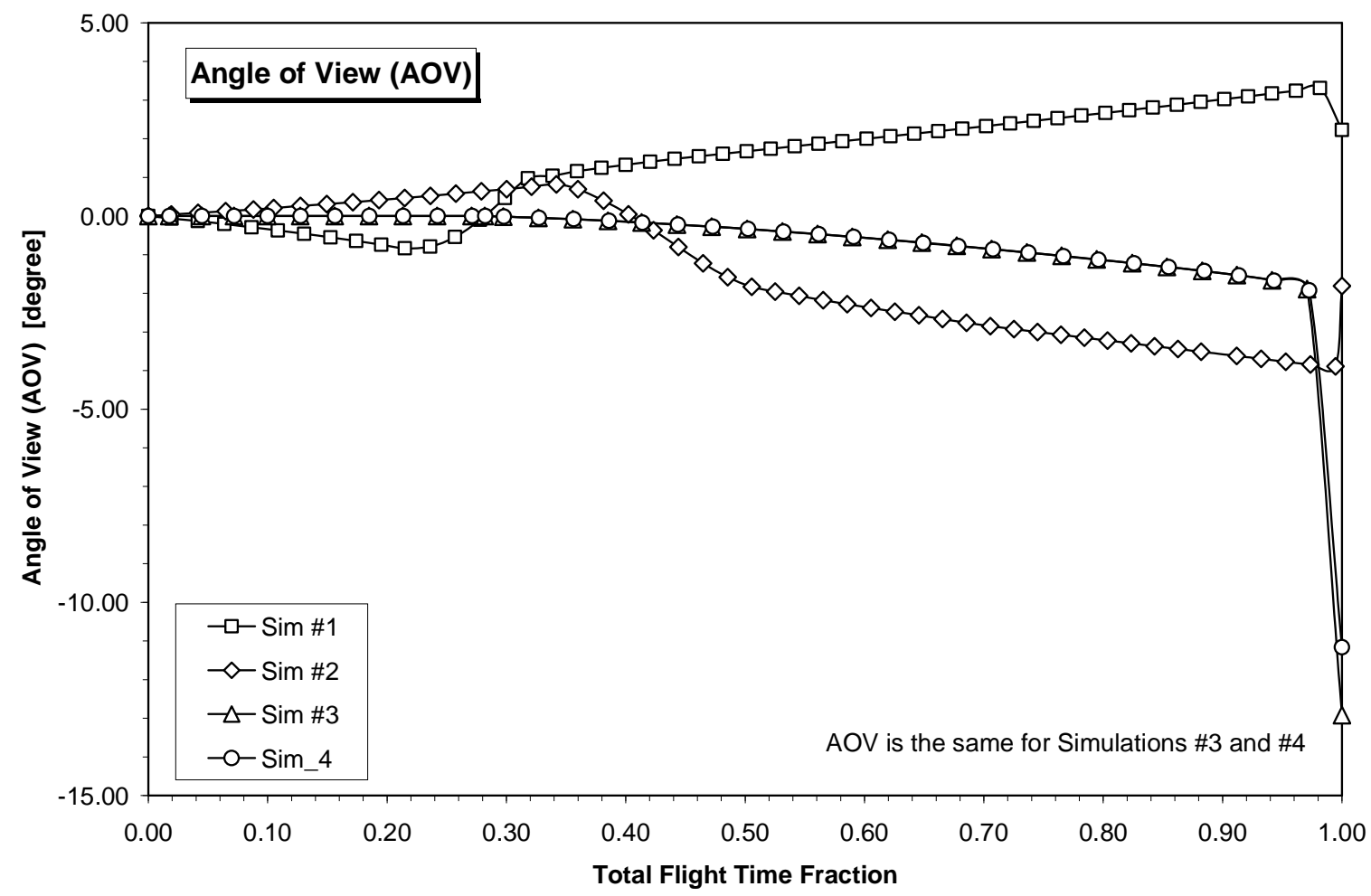

Figure 6: CLOS Angle of View (AOV) versus Total Flight Time Fraction 

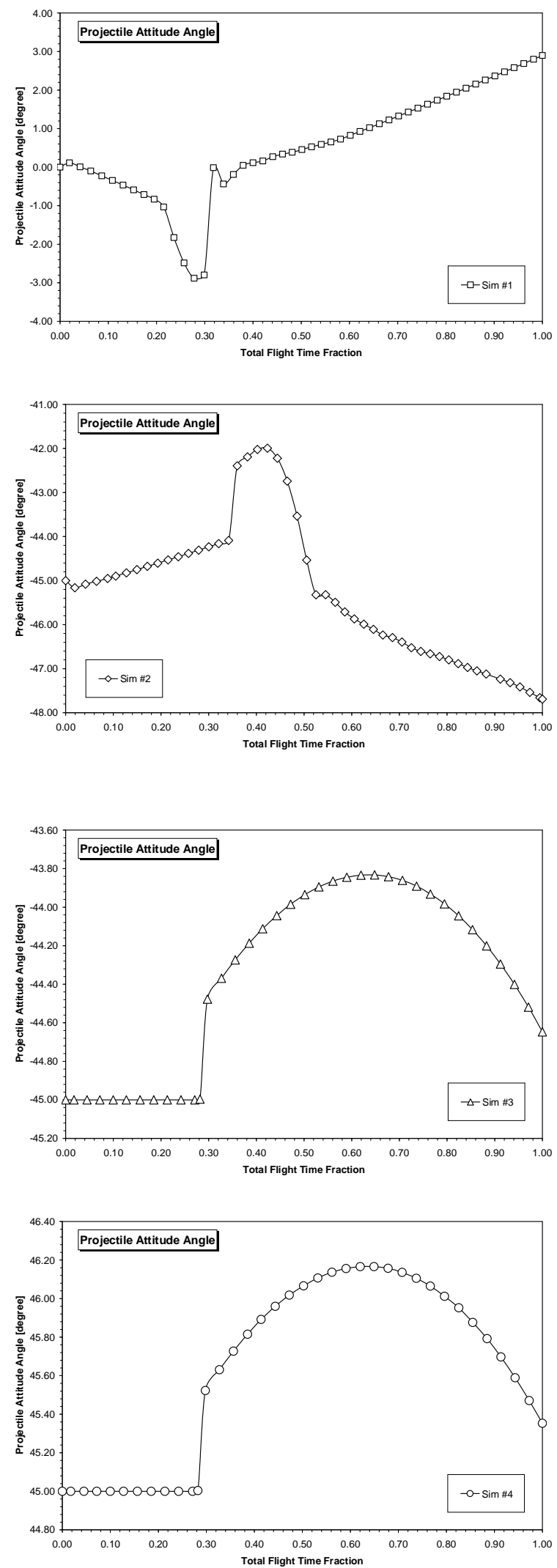

Figure 7: CLOS Projectile Attitude Angle versus Total Flight Time Fraction 


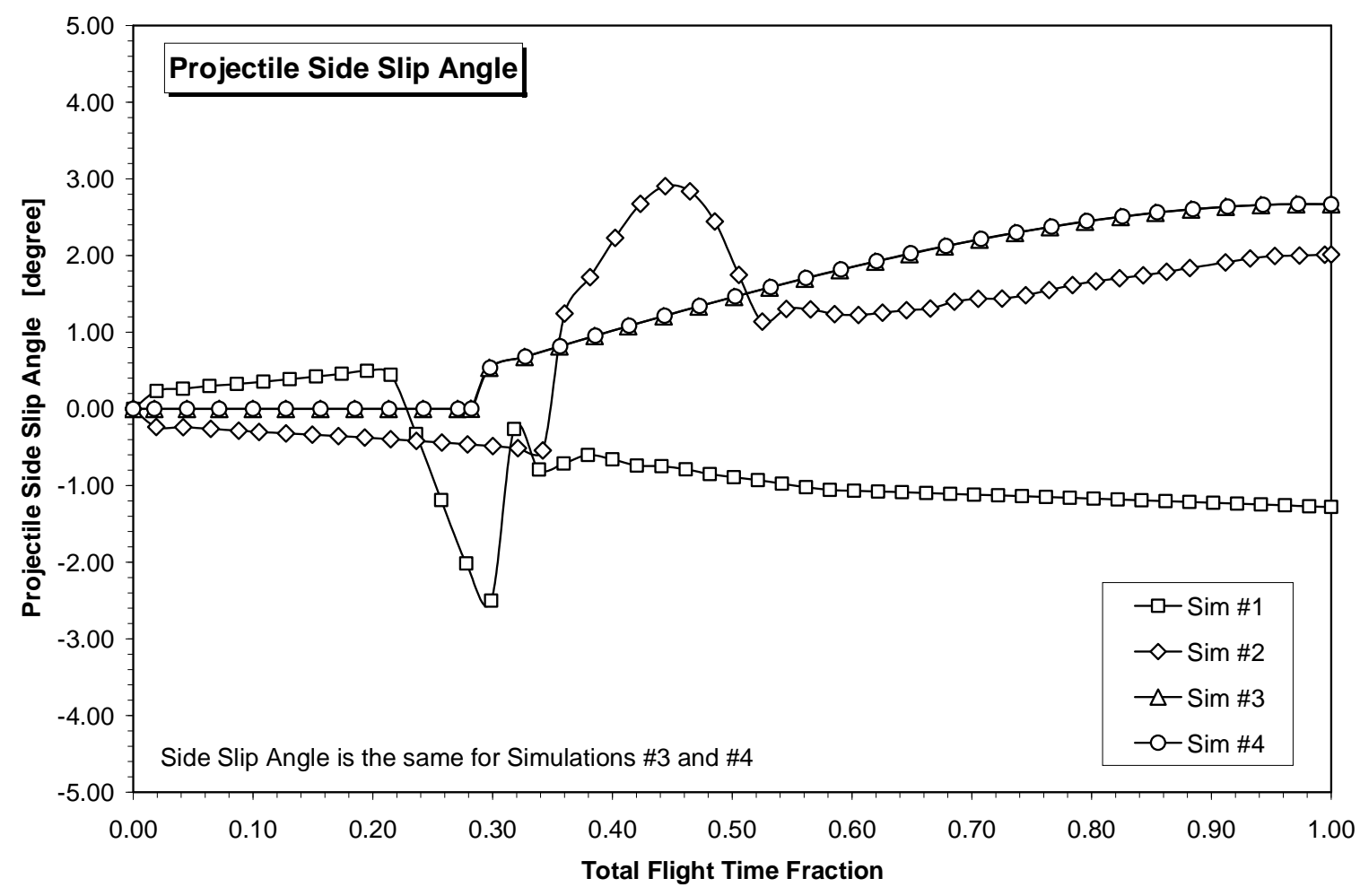

Figure 8: CLOS Projectile Side Slip Angle versus Total Flight Time Fraction

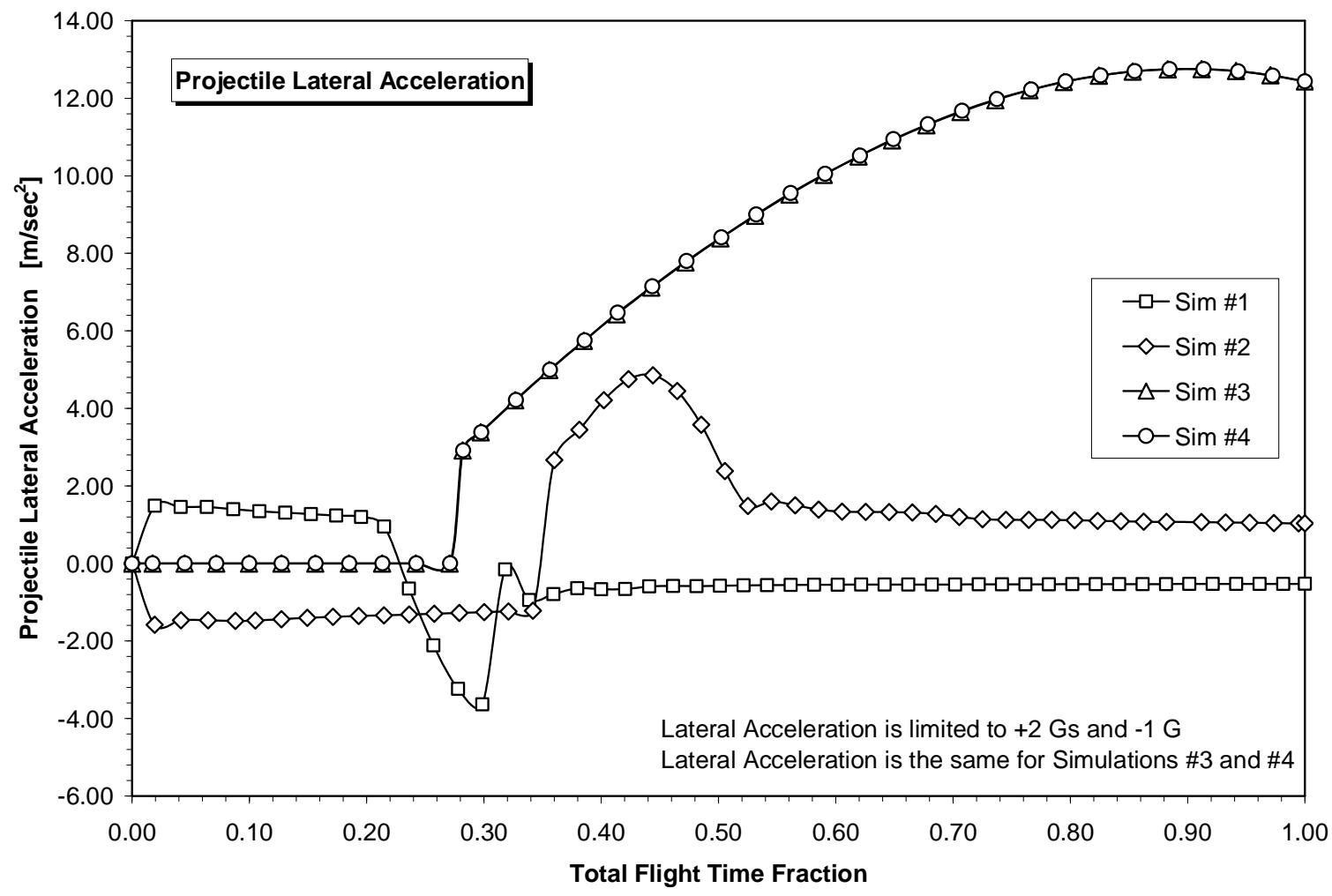

Figure 9: CLOS Projectile Lateral Acceleration versus Total Flight Time Fraction $10 / 13$ 


\begin{tabular}{|c|c|c|c|c|c|c|c|}
\hline Ue,Ve_P & $A y \_P \_d$ & $>$ Ue,Ve_P & $A y \_P \_d$ & $>$ Ue, Ve_P & Ay_P_d & Ue, Ve_P & Ay_P_d \\
\hline$>X e, Y e \_P$ & AOV & $>X e, Y e \_P$ & AOV & $>X e, Y e \_P$ & AOV & $X e, Y e \_P$ & $\mathrm{AOV}$ \\
\hline$>X e, Y e \_T$ & $\begin{array}{r}\left|r_{-} T-r_{-} P\right| \\
\text { LOS_D }\end{array}$ & \begin{tabular}{l|l} 
& $\mathrm{Xe}, \mathrm{Ye}{ }_{-} \mathrm{T}$ \\
$\mathrm{Ue}, \mathrm{Ve} \_\mathrm{T}$
\end{tabular} & $\left(r_{-}{ }^{T-r_{-}} P\right)$ & $>X e, Y e_{-} T$ & $\begin{array}{l}\left(r_{-} T-r_{P} P\right) \\
\text { LOS_D }\end{array}$ & $\begin{array}{l}\mathrm{Xe}, \mathrm{Ye} \mathrm{e}_{\mathrm{T}} \mathrm{T} \\
\mathrm{Ue}, \mathrm{Ve} \_\mathrm{T}\end{array}$ & $\begin{array}{r}\left(r_{-} T_{-} r_{-} P\right) \\
\text { LOS_D }\end{array}$ \\
\hline$>\mathrm{Ue}, \mathrm{Ve}{ }_{-} \mathrm{T}$ & L_D & $A e_{-} T$ & LOS_D & $>\mathrm{Ue}, \mathrm{Ve} \mathrm{C}_{\mathrm{T}} \mathrm{T}$ & L_D & $A e \_T$ & L_D \\
\hline$>A e_{-} \mathrm{T}$ & Gamma & >Ue_P0 & L_D & $>A e_{-} \mathrm{T}$ & Gamma & $n \_T$ & Gamma \\
\hline True Prop & Navigation & $\begin{array}{r}\text { Ve_Po } \\
\text { True Prc } \\
\text { Lir }\end{array}$ & $\begin{array}{l}\text { Gamma } \\
\text { lavigation } \\
\text { ONL) }\end{array}$ & \multicolumn{2}{|c|}{$\begin{array}{l}\text { True Proportional Navigation } \\
\text { (TPNZEMPLOS) }\end{array}$} & \multicolumn{2}{|c|}{$\begin{array}{c}\text { Augmented } \\
\text { Proportional Navigation } \\
\text { (APN) }\end{array}$} \\
\hline
\end{tabular}

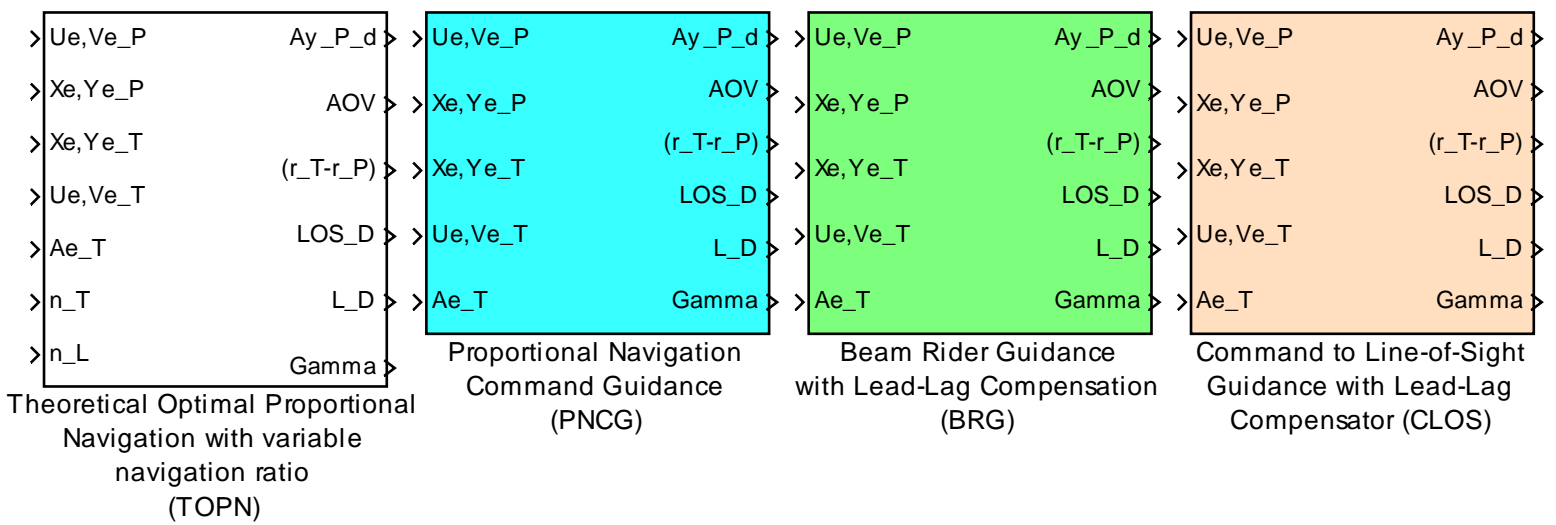

Figure 10: Guidance Law Blocks

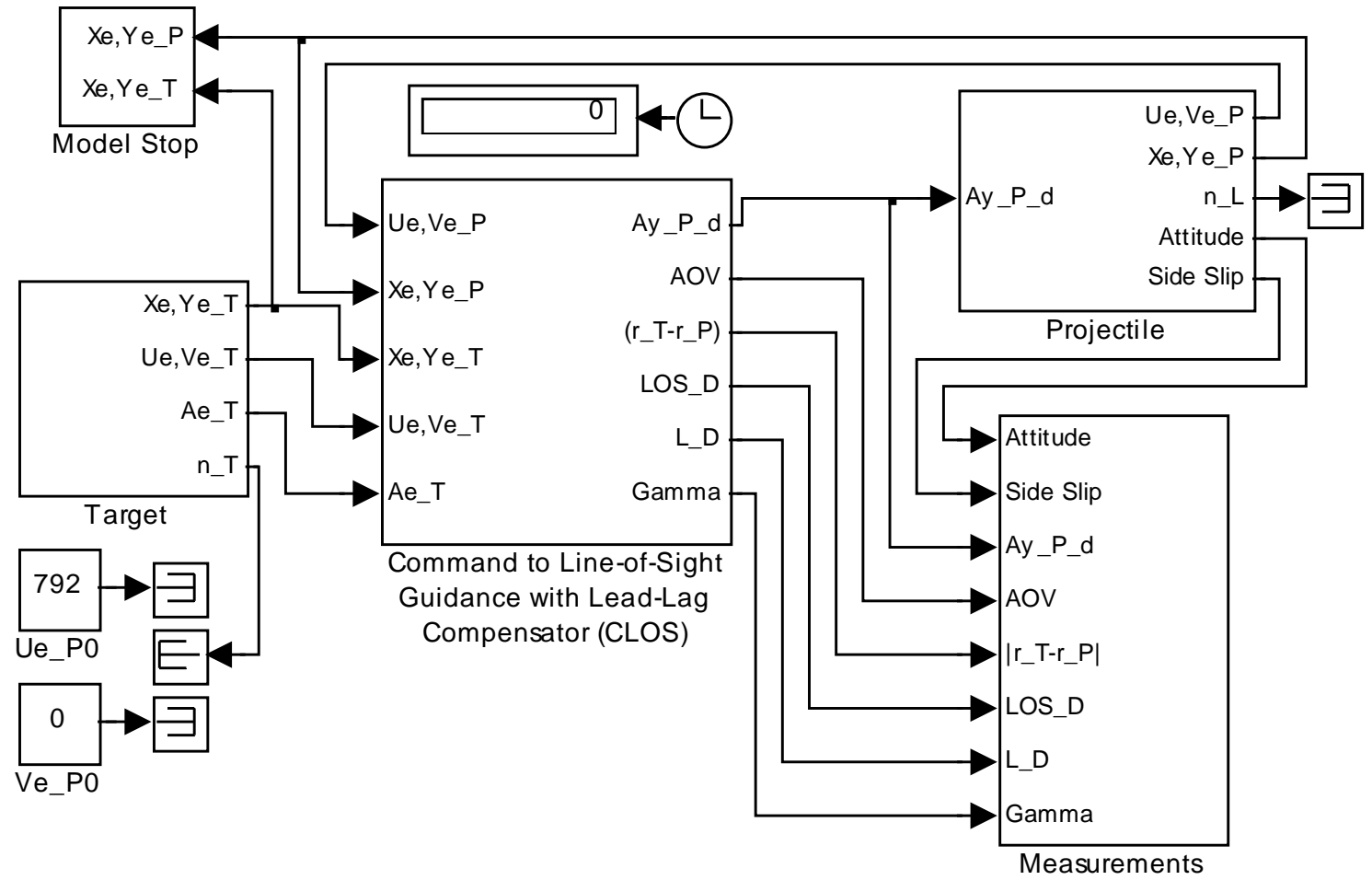

Figure 11: General Layout and Modules of the Simulation Model 


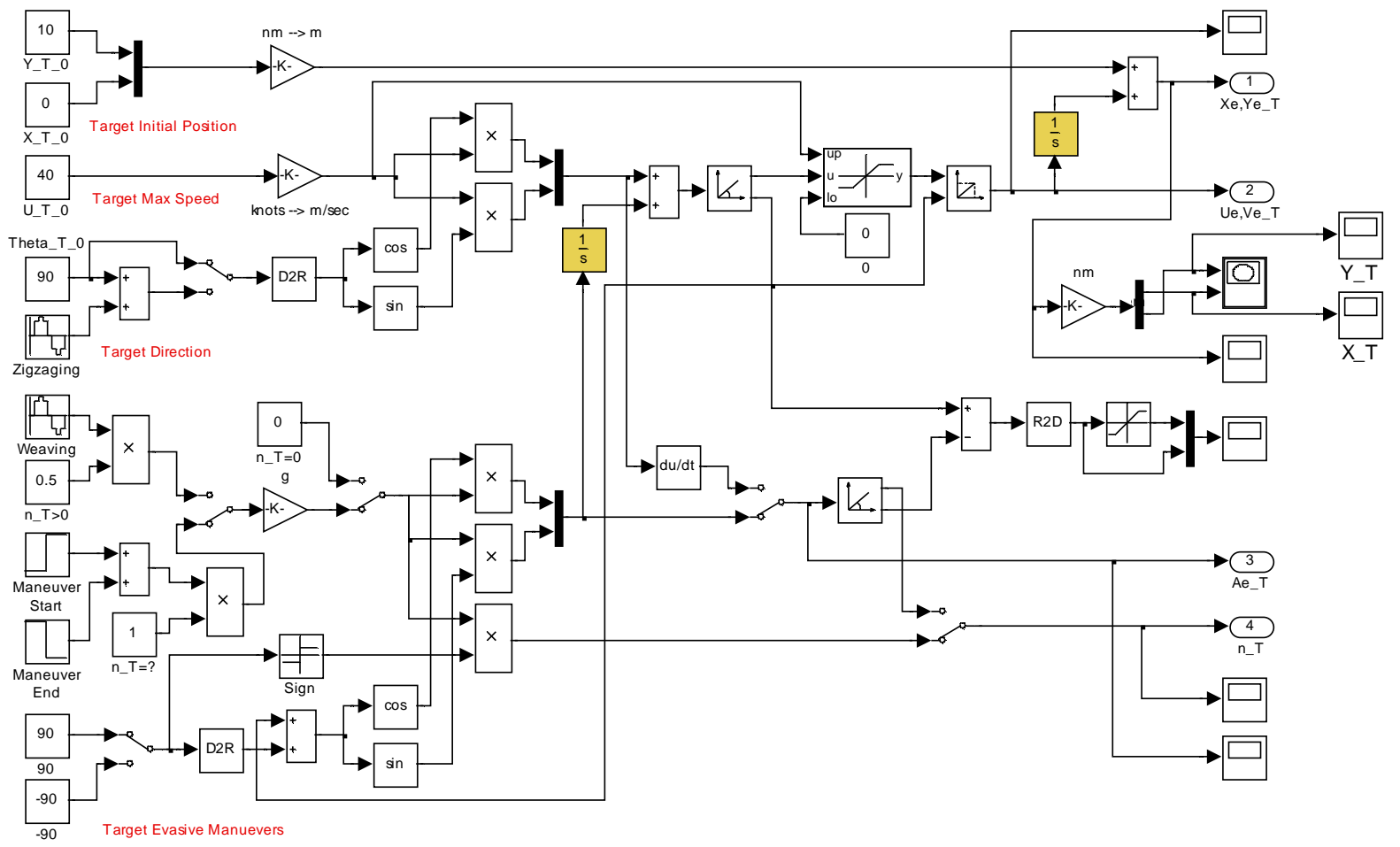

Figure 12: Target Parameters and Evasive Maneuvers Module

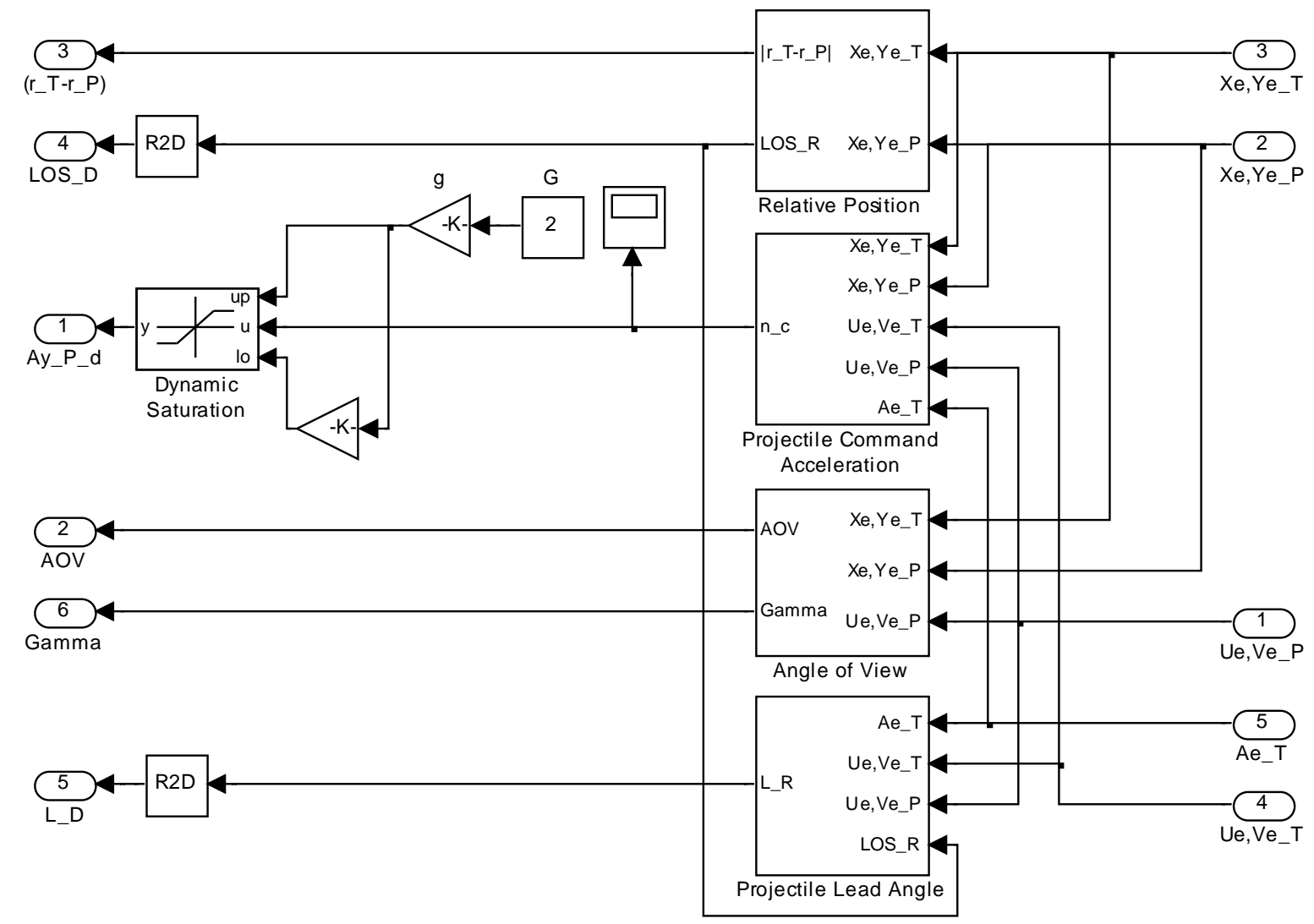

Figure 13: The CLOS Guidance Law Block Module 


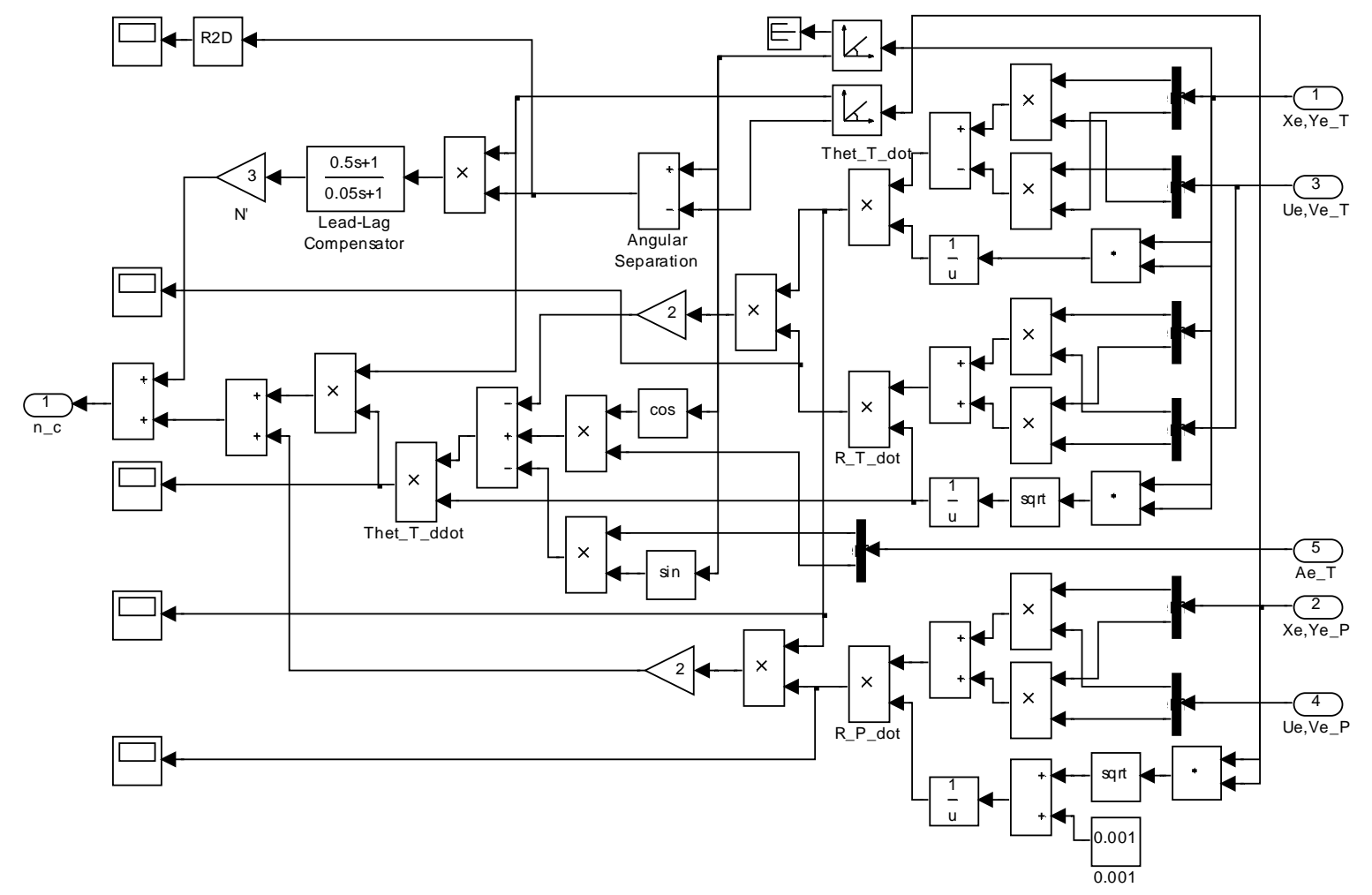

Figure 14: The CLOS Projectile's Command Acceleration Module

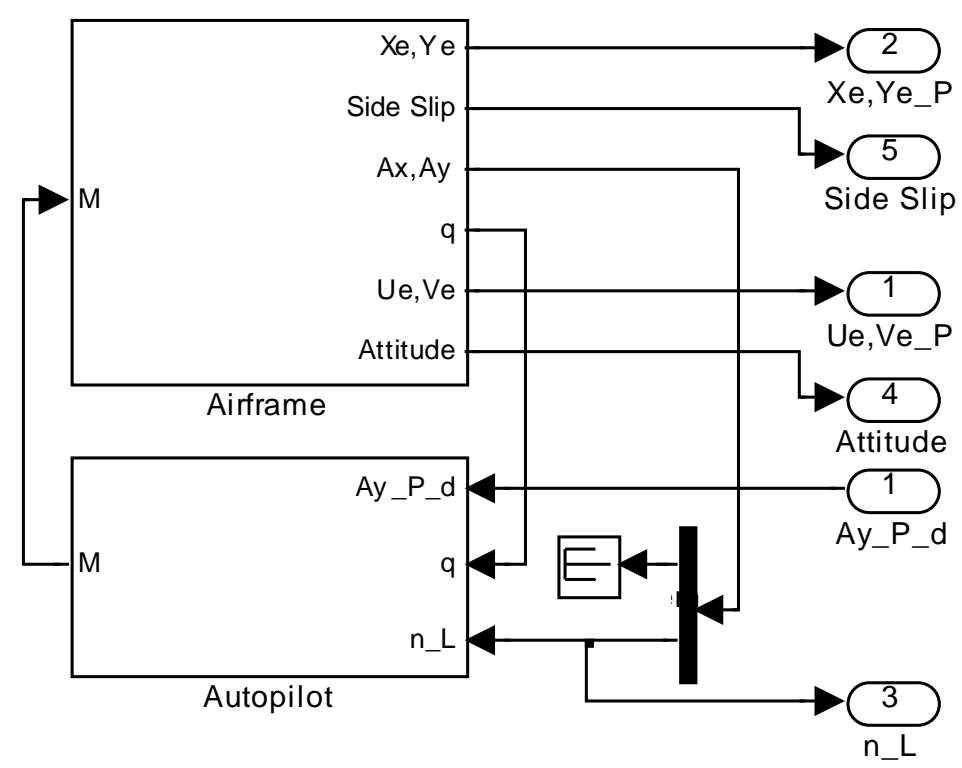

Figure 15: The Projectile Module 